\title{
Journal of Chemical Engineering \& Process Technology
}

\section{Removal of Crystal Violet and Hexavalent Chromium using $\mathrm{TiO}_{2}$-Bentonite under Sunlight: Effect of $\mathrm{TiO}_{2}$ Content}

Ridha Djellabi ${ }^{1}{ }^{2 *}$, Mohamed Fouzi Ghorab ${ }^{1}$, Claudia Letizia Bianchi ${ }^{2}$, Giuseppina Cerrato ${ }^{3}$ and Sara Morandi ${ }^{3}$

${ }^{1}$ Laboratory of Water Treatment and Valorization of Industrial Wastes, Chemistry Department, Faculty of Sciences, Badji-Mokhtar University, BP12 2300, Annaba, Algeria ${ }^{2}$ Università degli Studi di Milano, Dip. Chimica and INSTM-UdR Milano, Milano, Italy

${ }^{3}$ Università degli Studi di Torino, Dipartimento di Chimica and NIS Interdepartmental Centre and Consorzio INSTM-UdR Torino, Italy

\begin{abstract}
The main objective of this study was to investigate the correlation between $\mathrm{TiO}_{2}$ content in photoactive bentonite $\left(\mathrm{B}-\mathrm{TiO}_{2}\right)$ and the pathway by which crystal violet $(\mathrm{CV})$ and hexavalent chromium $(\mathrm{Cr}(\mathrm{VI}))$ are removed from water under sunlight. $\mathrm{B}-\mathrm{TiO}_{2}$ samples were prepared by impregnation with $\mathrm{TiCl}_{4}$ with different weight ratios $(\mathrm{g} / \mathrm{g})$ (namely, $5,10,20$ and $30 \%$ ). Materials were characterized using different techniques, among which: SEM, FT-IR, XRD, HRTEM, EDX and Zeta potential measurements. Results show that, only the anatase $\mathrm{TiO}_{2}$ polymorph was formed in the bentonite and the porosity of materials decreases with the increase of $\mathrm{TiO}_{2}$ content. Furthermore, zeta potential measurements indicate that, when $\mathrm{TiO}_{2}$ content increases, the negative charge of materials decreases. On the other hand, experimental results show that these materials combine both adsorption and photocatalytic reactions to remove $\mathrm{CV}$ molecules from water. As the $\mathrm{TiO}_{2}$ content increases, the adsorption capacity decreases, while the photocatalytic activity is more important. In the case of $\mathrm{Cr}(\mathrm{VI})$ species, all samples show a few adsorption because of the repulsion effect between these species and the negative charge of the bentonite. Therefore, under sunlight, the $\mathrm{Cr}(\mathrm{VI})$ removal occurred mainly by the photoreduction reaction that is more efficient when the $\mathrm{TiO}_{2}$ content increases.
\end{abstract}

Keywords: Bentonite- $\mathrm{TiO}_{2} ; \mathrm{TiO}_{2}$ content; Water remediation; Photoactivity; Sunlight

\section{Introduction}

Among the challenges that our world is nowadays facing, water resources and their scarceness could be considered as important for the human, particularly with the increase of the world population. In this respects, the remediation of both water and wastewaters has become a global strategy in order to decrease the dependency from natural water resources. Moreover, industrial effluents are the main causes of water pollution by different pollutants, such as heavy metals and dyes.

Several technologies are available for the treatment of wastewaters. Among these, the Advanced Oxidation Processes (AOPs) have been and are still extensively investigated [1]. Among these techniques, photocatalysis is an efficient method, environmentally friendly and low cost point-of-use treatment technology for wastewater purification. It focuses on the production of high oxidizing species which can mineralize organics in water [2]. Furthermore, it can reduce heavy metal species to low or metallic states by electrons coming from the conduction band [3-5]. $\mathrm{TiO}_{2}$ is usually used in photocatalytic remediation for both oxidation and reduction of different pollutant species due to its excellent chemical and optical properties $[5,6]$. The efficiency rate of the photocatalytical treatment by $\mathrm{TiO}_{2}$ depends on pollutant concentration in the $\mathrm{TiO}_{2}$ vicinity, optical proprieties, adsorptive capacity as well as both the number of electrons and radicals produced. Many researcher groups have developed novel generation of photocatalysts in order to overcome different drawbacks of the commercial ones. One of the most applied strategies to enhance the photoeffeciecy is the immobilization of $\mathrm{TiO}_{2}$ on porous adsorbent materials [7-9]. Accordingly, economic reasons explain why the development of re-usable natural clays as $\mathrm{TiO}_{2}$ supports is attracting increasing interest [10-12]. Among these applied clay minerals, montmorillonite is frequently used. It possesses a layered structure, large external and internal surface area, high cation exchange capacities and it can adsorb organics/cations either on its external surface or within its interlaminar spaces by interaction or substitution $[13,14]$. In general, the dispersion of $\mathrm{TiO}_{2}$ particles into layered montmorillonite improves the photoactivity performance because such composite structure can stabilize $\mathrm{TiO}_{2}$ particles and maintain most of the surface of $\mathrm{TiO}_{2}$ crystals for access by various species. Forthermore, adsorption capacity of this material can participate to adsorb molecules and by-products.

In our previous work, we investigated the preparation of $\mathrm{TiO}_{2}-$ Montmorillonite composite $\left(\mathrm{B}-\mathrm{TiO}_{2}\right)$ by impregnation of a local sodium-bentonite (B-Na) with $\mathrm{TiCl}_{4}$ for the decomposition of different dyes under UV irradiation [15]. Results showed that this material involves both adsorption and photocatalytic action for the removal of dyes from water, while both adsorption effectiveness and photocatalytic degradation were more pronounced for cationic dyes.

In the present work, we studied the effect of $\mathrm{TiO}_{2}$ loading in the $\mathrm{TiO}_{2}$-Montmorillonite composite on the degradation of a cationic dye (crystal violet) and the reduction of hexavalent chromium under natural sunlight. A series of $\mathrm{TiO}_{2}$-Montmorillonite composites have been prepared with different $\mathrm{TiO}_{2}$ content. Photocatalyst materials were characterized using different methods such as SEM, FT-IR, XRD, HR-TEM, EDX and Zeta potential measurements.

*Corresponding author: Ridha Djellabi, Chemistry Department, BadjiMokhtar University, and BP12 2300, Annaba, Algeria, Tel: 213774662262 ; E-mail: ridha.djellabi@yahoo.com

Received February 09, 2016; Accepted February 25, 2016; Published February 29,2016

Citation: Djellabi R, Ghorab MF, Bianchi CL, Cerrato G, Morandi S (2016) Removal of Crystal Violet and Hexavalent Chromium using $\mathrm{TiO}_{2}$-Bentonite under Sunlight: Effect of $\mathrm{TiO}_{2}$ Content. J Chem Eng Process Technol 7: 276. doi:10.4172/2157. 7048.1000276

Copyright: @ 2016 Djellabi R, et al. This is an open-access article distributed under the terms of the Creative Commons Attribution License, which permits unrestricted use, distribution, and reproduction in any medium, provided the original author and source are credited. 


\section{Materials and Methods}

\section{Materials}

The montmorillonite used in this study is a natural sodiumexchanged bentonite (Na-B) from the Roussel deposit in Maghnia (Algeria) and was used without any further treatment or purification. Its cation-exchange capacity was determined by the methylene blue method and is $89.30 \mathrm{mmol} / 100 \mathrm{~g}$. Solutions were prepared using double-distilled water. Crystal violet (Fluka), a cationic dye, was used in this study. Hexavalent chromium solution was prepared from potassium dichromate (Sigma-Aldrich, $\geq 99.0 \%$ ). Adjustment of the $\mathrm{pH}$ solution was achieved with $\mathrm{H}_{2} \mathrm{SO}_{4}$ (Sigma-Aldrich) and monitored by a pH meter (HANNA HI 9812-5). Tartaric acid (Sigma-Aldrich, ACS reagent, $\geq 99.5 \%$ ) was used as a holes scavenger for $\mathrm{Cr}(\mathrm{VI})$ reduction.

\section{Synthesis of titania-montmorillonite}

Titania-montmorillonite $\left(\mathrm{B}-\mathrm{TiO}_{2}\right)$ samples were prepared by $\mathrm{B}-\mathrm{Na}$ impregnation with $\mathrm{TiCl}_{4}$ (Aldrich, 99.99\%) at different weight ratios $(\mathrm{g} / \mathrm{g})(5,10,20$ and $30 \%)$. The experimental synthesis procedure was reported in our previous paper [15].

\section{Characterization methods}

Fourier transform infrared (FT-IR) spectra of $\mathrm{Na}-\mathrm{M}$ and $\mathrm{TiO}_{2}-\mathrm{M}$ (as self-supporting pellets, $\sim 20 \mathrm{mg} \mathrm{cm}^{-2}$ ) were recorded at room temperature at a $2 \mathrm{~cm}^{-1}$ resolution in the $4000-400 \mathrm{~cm}^{-1}$ spectral range using a PerkinElmer FT-IR System 2000 spectrophotometer, equipped with a Hg-Cd-Te cryo-detector. The self-supporting pellets were posed in a quartz cell equipped with $\mathrm{KBr}$ windows: before recording the FTIR spectra, all samples have been activated in vacuo at room temperature (RT) connecting the cell to a vacuum line (residual pressure $<10^{-4}$ mbar).

The XRD patterns were recorded on a diffractometer instrument (Philips PW3830/3020 X'Pert diffractometer, PANalytical) using monochromatized $\mathrm{CuK}_{\alpha}$ radiation $(\lambda=1.54 \AA)$. The inter-layer $\mathrm{d}$-spacing reflection was calculated using the Bragg equation [16]. The crystallite size of anatase $\mathrm{TiO}_{2}$ was calculated using Scherrer's formula.

The morphology of samples particles was determined by field emission scanning electron microscopy (FEG LEO 1525, Zeiss Company, Germany) and (High-resolution) Transmission electron microscopy (HR-TEM) images were obtained employing a JEOL JEM 3010 UHR $(300 \mathrm{kV})$ microscope $(300 \mathrm{kV}$ acceleration, single crystal $\mathrm{LaB}_{6}$ filament) fitted with an Oxford INCA Energy TEM 200 energy dispersive $\mathrm{X}$-ray (EDX) detector. Before inspection, all samples were dry deposited on $\mathrm{Cu}$ "holey" carbon grids (200 mesh).

Zeta potential measurements of samples were carried out using a Zetasizer 2000 instrument equipped with a microprocessor at a temperature of $25^{\circ} \mathrm{C}$. The zeta meter automatically calculates the electrophoretic mobility of the particles and converts it to the zeta potential using the Smoluchowski equation as follow:

$$
\zeta=\left[4 \pi \frac{\mathrm{v}_{\mathrm{t}}}{\mathrm{D}_{\mathrm{t}}}\right] \mathrm{EM}
$$

Where $\zeta$ is zeta potential, EM is electrophoretic mobility at actual temperature, $v_{t}$ is the viscosity of the suspending distilled water, and $\mathrm{D}_{t}$ is dielectric constant.

\section{Photocatalytic tests}

The photocatalytic experiments were performed using a static batch reactor, consisting of Pyrex beakers open to air under natural sunlight at sea level (in front of the Chemistry Department without any obstacle) on sunny days (at Annaba University) and were started at 10:00 am for a duration of 4 h. $250 \mathrm{~mL}$ Solutions of crystal violet ([CV]: $\left.10^{-4} \mathrm{M}, \mathrm{pH}: 6.5\right)$ and hexavalent chromium ([Cr (VI): $30 \mathrm{ppm}, \mathrm{pH}: 2.2$ ) were exposed to natural sunlight under a constant stirring. Adsorption experiments were performed under the same conditions without irradiation. During the experiments, samples $(4 \mathrm{~mL})$ were collected at selected time intervals. The photocatalyst was removed by filtration $(0.45 \mu \mathrm{m}$, Whatman). The residual concentration of $\mathrm{Cr}(\mathrm{VI})$ species was determined at a wavelength of $540 \mathrm{~nm}$ via the 1,5-diphenylcarbazide (DPC) method [17]. Furthermore, the residual concentration of CV was determined at a wavelength of $590 \mathrm{~nm}$. The intensity of sunlight radiation at $365 \mathrm{~nm}$ was measured using a VLX-3W radiometer (Vilber Loumart, France) with a cell diameter of $1 \mathrm{~cm}^{2}$ : it always was in the 16 to $18 \mathrm{~W} / \mathrm{m}^{2}$ range during the experimental period. The extent of water evaporation during the solar photocatalysis experimental was in average of $6.0 \%$ in volume after $4 \mathrm{~h}$ of irradiation and was considered to be within the experimental errors.

\section{Results and Discussion}

\section{Characterization of photocatalysts}

SEM: Figure 1 reports SEM images of $\mathrm{Na}-\mathrm{B}, \mathrm{B}-\mathrm{TiO}_{2}(10 \%)$ and $\mathrm{B}-\mathrm{TiO}_{2}(30 \%)$ samples. Both porosity and integrated flakes-like structure of the B-Na material are evident: see the top images in Figure 1. Porosity of bentonite, including intra-particles, interparticles and inter-aggregates, is a suitable feature for the intercalation of $\mathrm{TiO}_{2}$ particles. Furthermore, pollutants can be accumulated inside pores and onto the surface. However, images of $\mathrm{B}-\mathrm{TiO}_{2}(10 \%)$ and $\mathrm{B}-\mathrm{TiO}_{2}$ (30\%) show a clear changing of the bentonite morphology, evidencing the appearance of $\mathrm{TiO}_{2}$ spheroids. In the case of $\mathrm{B}-\mathrm{TiO}_{2}(30 \%)$, the high concentration of $\mathrm{TiO}_{2}$ causes the formation of aggregates (Figure 1, section "a" at bottom) which can reduce the porosity of this material. This observation will be confirmed by XRD analysis.

XRD: Figure 2 reports the XRD results obtained for all samples, also compared with those typical of a commercial pure anatase $\mathrm{TiO}_{2}$ (Kronos 1077). $\mathrm{TiO}_{2}$ in this form is well evident in samples $\mathrm{B}_{-} \mathrm{TiO}_{2}$ (10\%), $\mathrm{B}-\mathrm{TiO}_{2}(20 \%)$ and $\mathrm{B}-\mathrm{TiO}_{2}(30 \%)$. On the contrary, the sample containing $5 \%$ of $\mathrm{TiO}_{2}$ exhibits no peaks related to the presence of $\mathrm{TiO}_{2}$ : this may be reasonably due to the fact that the amount of $\mathrm{TiO}_{2}$ is under the detection limit of the technique.

The pure bentonite B-Na shows the peculiar peak located at $5.8^{\circ}$ and related to the basal spacing reflection of montmorillonite. On the other hand, all the $\mathrm{B}-\mathrm{TiO}_{2}$ samples exhibit two components in this region. As already reported in our previous paper [15], the two components are a clear indication that the introduction of $\mathrm{TiO}_{2}$ could bring about a decreasing of the basal spacing of a part of the montmorillonitic material. It is worth of note that the sample with the lowest amount of $\mathrm{TiO}_{2}$ shows the highest relative intensity of the component at higher angles, i.e., the peak arising from the $\mathrm{TiO}_{2}$ insertion in the basal spaces of montmorillonite. As far as the $\mathrm{TiO}_{2}$ content increases, the relative intensity of this component decreases. This result can reasonably suggest that only a small part of $\mathrm{TiO}_{2}$ is introduced in the basal spaces and this amount is inversely proportional to the $\mathrm{TiO}_{2}$ loading in the sample.

Moreover, the basal space related to the peak at the highest angles is about $14 \AA$ and the mean particle size of $\mathrm{TiO}_{2}$, calculated by the Scherrer's equation on the main peak (101), is quite coherent with the basal space, being in the range $14-20 \AA$ for all the $\mathrm{B}-\mathrm{TiO}_{2}$ samples. 
Citation: Djellabi R, Ghorab MF, Bianchi CL, Cerrato G, Morandi S (2016) Removal of Crystal Violet and Hexavalent Chromium using TiO ${ }_{2}-\mathrm{Bentonite}$ under Sunlight: Effect of $\mathrm{TiO}_{2}$ Content. J Chem Eng Process Technol 7: 276. doi:10.4172/2157-7048.1000276

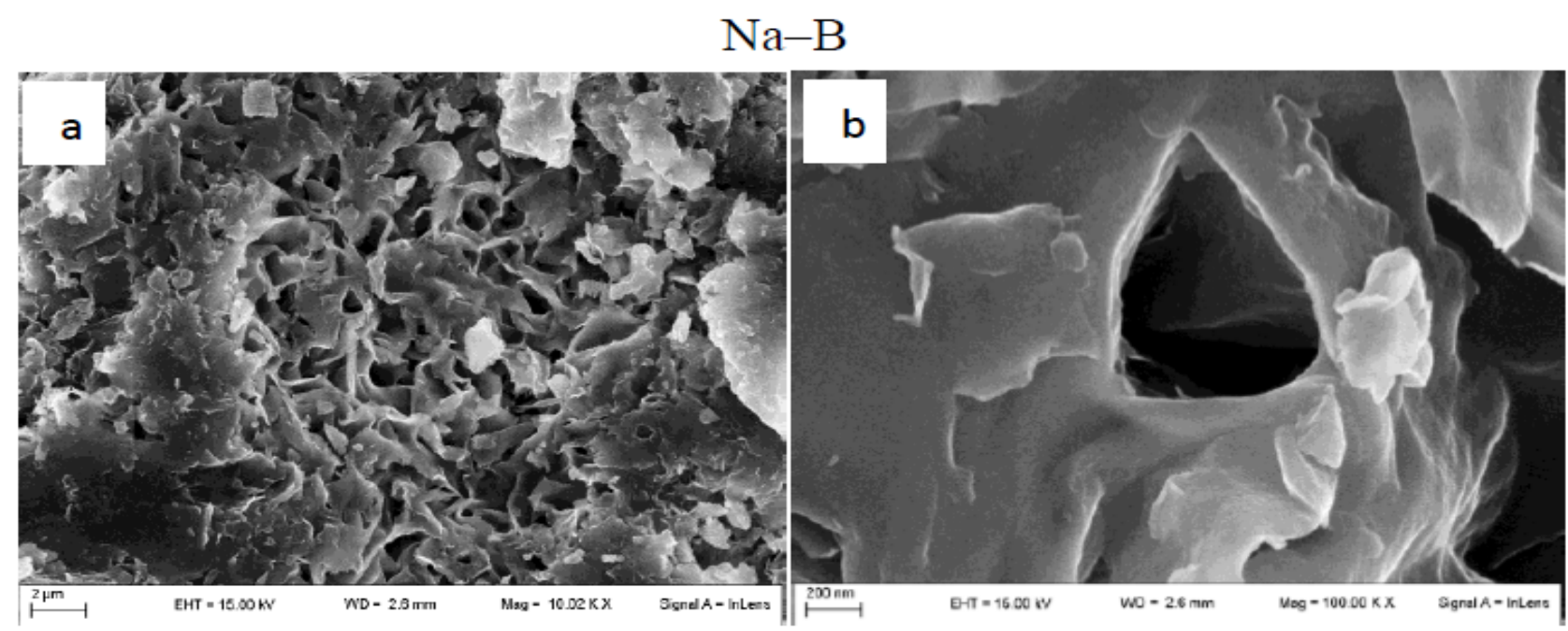

\section{$\mathrm{B}-\mathrm{TiO}_{2}(10 \%)$}

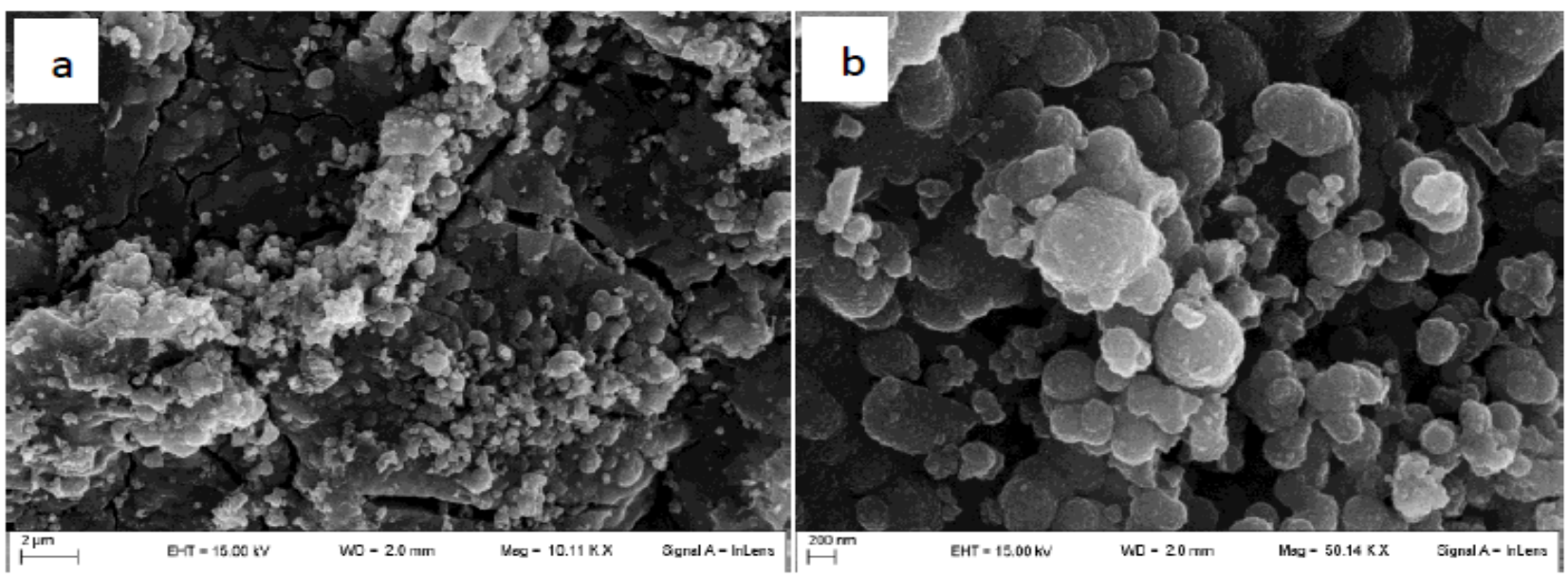

\section{$\mathrm{B}-\mathrm{TiO}_{2}(30 \%)$}

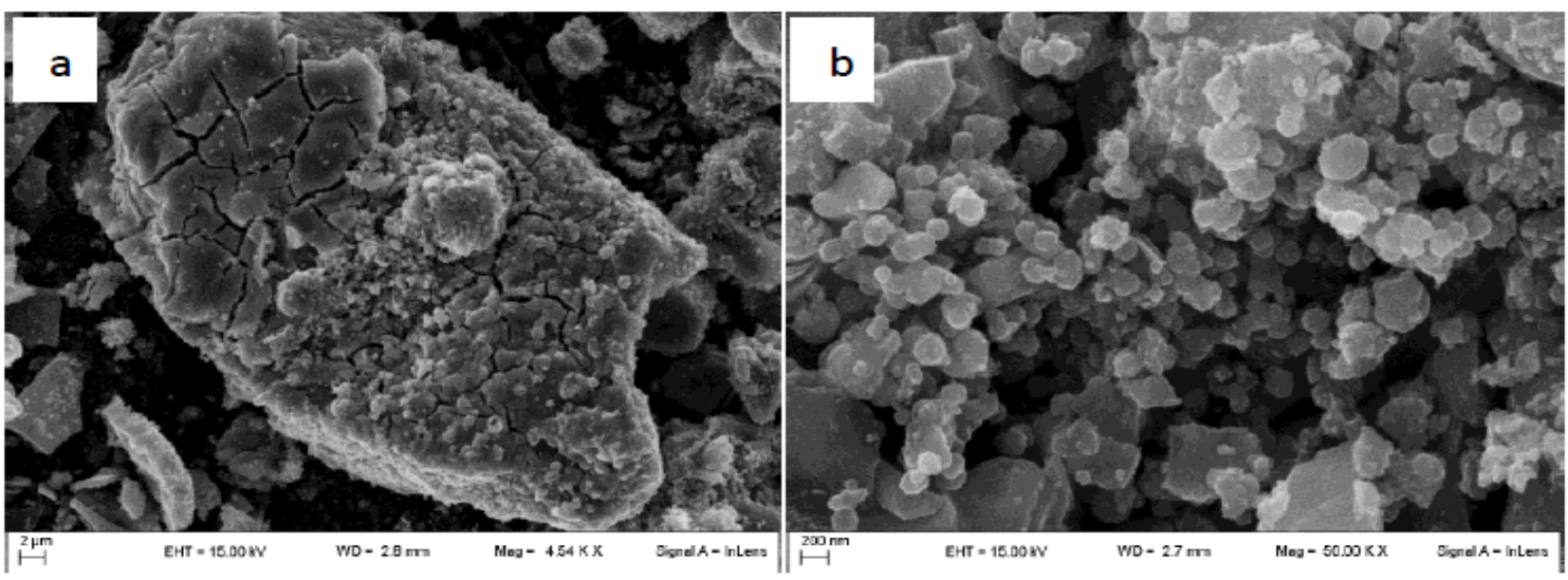

Figure 1: SEM images of samples at (a): $2 \mu \mathrm{m}$ and (b): $200 \mathrm{~nm}$. 
Citation: Djellabi R, Ghorab MF, Bianchi CL, Cerrato G, Morandi S (2016) Removal of Crystal Violet and Hexavalent Chromium using TiO ${ }_{2}$-Bentonite under Sunlight: Effect of $\mathrm{TiO}_{2}$ Content. J Chem Eng Process Technol 7: 276. doi:10.4172/2157-7048.1000276

FTIR spectra: Figure 3 reports the FTIR spectra of all the samples under investigation. As already reported in our previous work [15], after outgassing at $\mathrm{RT}$, spectra of $\mathrm{B}-\mathrm{Na}$ and $\mathrm{B}-\mathrm{TiO}$, samples exhibit bands in the $3700-3000 \mathrm{~cm}^{-1}$ range that can be assigned to the stretching vibration modes of all (either structural and/or surface) $\mathrm{OH}$ groups interacting by $\mathrm{H}$-bonding. The spectroscopic counterpart of these modes can be observed at $\sim 1630 \mathrm{~cm}^{-1}$ (bending mode of undissociated $\mathrm{H}_{2} \mathrm{O}$ molecules). Moreover, in the $2000-1700 \mathrm{~cm}^{-1}$ range a complex envelope of bands is present for all the $\mathrm{B}-\mathrm{TiO}_{2}$ materials: it can be assigned to the typical overtones of the $\mathrm{SiO}_{2}$-like matrix. On the other hand, it is worth noting that B-Na exhibits a complex spectral component at $\sim 1490 \mathrm{~cm}^{-1}$ : this component, totally absent in the case of all $\mathrm{B}-\mathrm{TiO}_{2}$ samples, is ascribable to some modes typical of carbonate anions. The absence of this component can be related to the addition of $\mathrm{TiO}_{2}$, as reasonably in the synthetic step the anions, present in the interlayers of the montmorillonite material, are totally substituted by the anions formed by titanium-containing species. In the calcination step, the presence of the latter species brings about the formation of $\mathrm{TiO}_{2}$ and leads to the retaining of a higher amount of water, as evidenced in $\mathrm{B}_{-} \mathrm{TiO}$, spectra: the envelope assigned to the $\mathrm{OH}$ stretching mode(s) and the component located at $1630 \mathrm{~cm}^{-1}$ are larger/more intense in the case of all $\mathrm{B}-\mathrm{TiO}_{2}$ samples than in the case of pure $\mathrm{B}-\mathrm{Na}$.

HR-TEM-EDX: As far as the general morphology of the particles is concerned, the indications coming from XRD/FTIR for both $\mathrm{B}-\mathrm{TiO}_{2}(5 \%)$ and $\mathrm{B}-\mathrm{TiO}_{2}(20 \%)$ are confirmed: in the case of $\mathrm{B}-\mathrm{TiO}$ (5\%) powder the typical features of a interlayered system are evident, whereas almost no trace of the presence of $\mathrm{TiO}_{2}$ particles is observable, even at high magnification (see the inset in the TEM images, Figure 4). Nevertheless, the presence of $\mathrm{TiO}_{2}$ is confirmed by the EDX spectrum, see Figure 5: this apparent contradiction is not unexpected, as the $\mathrm{TiO}_{2}$ particles can be very small (under the detection limit of the TEM technique) or, more likely, they are present in very limited extent due to the very low $\mathrm{TiO}_{2}$ amount. The presence of all the other elements in the EXD spectrum confirms the montmorillonitic nature of the powder.

In the case of the $20 \% \mathrm{TiO}_{2}$ montmorillonite powder, the morphological features are totally different (Figure 6): even though large areas ascribable to the native interlayered system are still observable (see the left-hand section of Figure 6), the general morphology is totally upset, if compared to the $5 \% \mathrm{TiO}_{2}$-containing system. In fact, a lot of small highly ordered crystalline particles are now present (see both central and right-hand sections). The average sizes of these newly formed particles, characterized by rather sharp edges and being very thin and closely packed, fall in the $5-20 \mathrm{~nm}$ range and the detailed inspection of the fringe patterns indicate the presence of the (101) family planes of the anatase $\mathrm{TiO}_{2}$ polymorph (ICDD card no. 21-1272).

A further proof of the upsetting of the interlayered system comes from the EDX spectrum of this sample (Figure 7): the Ti peak (being present in the form of $\mathrm{TiO}_{2}$ ) is now the prevalent component, whereas the other typical species connected to montmorillonite are present to a limited extent.

Zeta potential: Zeta potential mesurements of all samples, which reflect the electrical potential in the double layer at the interface between a bentonite particle and the surrounding liquid, are reported in Figure 8 and Table 1. The magnitude of this parameter is often used as a measure of the strength of the attractive/repulsive interactions between particles and to have information about the surface property of the particles in suspension. It is worth to note that all photocatalyst samples have negative zeta potentials, which indicate that these materials are negatively charged in water. This behaviour is not unusual

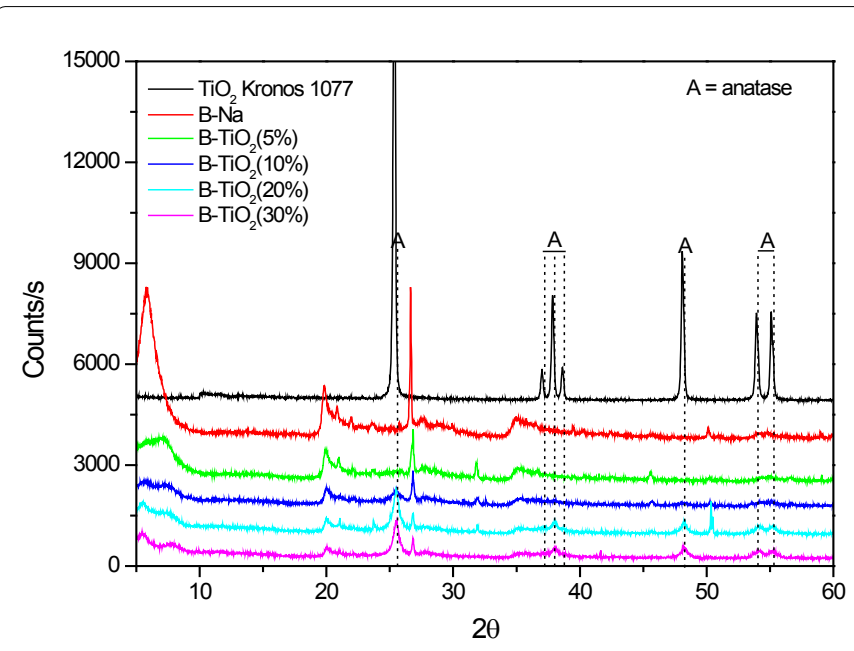

Figure 2: XRD patterns of photocatalyst samples.

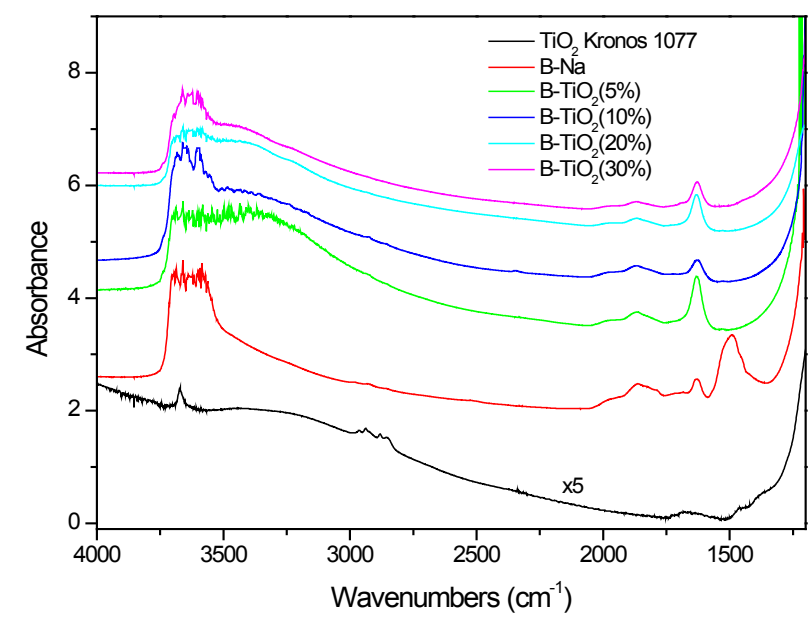

Figure 3: FTIR spectra of photocatalyst samples after outgassing at RT.

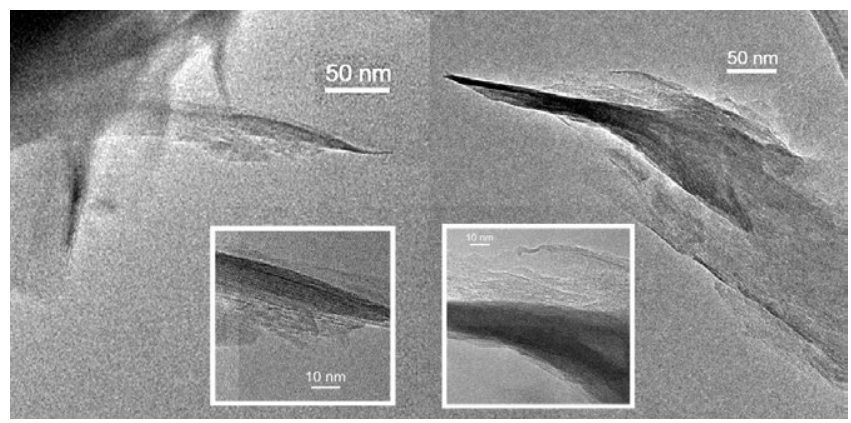

Figure 4: HR-TEM images of $\mathrm{B}-\mathrm{TiO}_{2}(5 \%)$ sample.

for the bentonite. It is known that the permanent negative charge is very high in bentonite accounting for $90-95 \%$ of the total charges [18]. This is due to the high degree of isomorphic substitution where the Al (III) element in the octahedral sheet are substituted by either Fe (II) or $\mathrm{Mg}(\mathrm{II})$, in addition to some $\mathrm{Si}(\mathrm{IV})$ in the tetrahedral layer being substituted by $\mathrm{Al}(\mathrm{III})$. These permanent charges located on the basal face account for most of the surface charge density of the bentonite. This 
Citation: Djellabi R, Ghorab MF, Bianchi CL, Cerrato G, Morandi S (2016) Removal of Crystal Violet and Hexavalent Chromium using TiO ${ }_{2}$-Bentonite under Sunlight: Effect of $\mathrm{TiO}_{2}$ Content. J Chem Eng Process Technol 7: 276. doi:10.4172/2157-7048.1000276

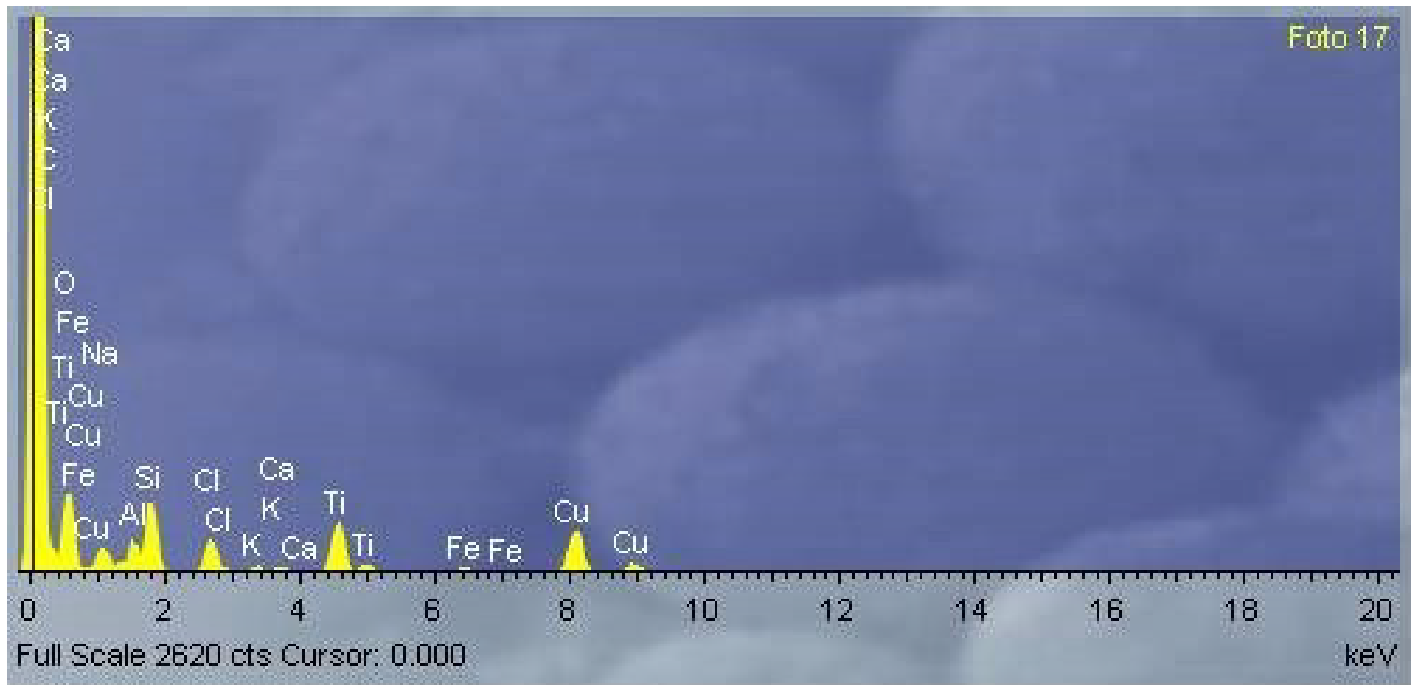

Figure 5: EDX spectrum of $\mathrm{B}-\mathrm{TiO}_{2}(5 \%)$ sample.

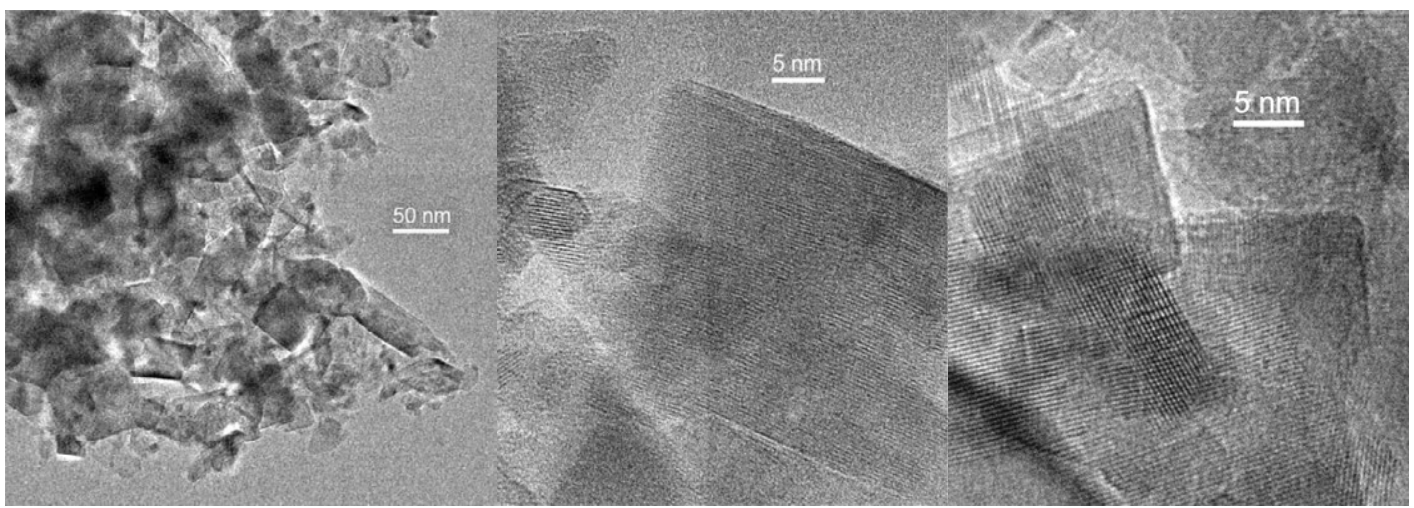

Figure 6: HR-TEM images of $\mathrm{B}-\mathrm{TiO}_{2}(20 \%)$ sample.

explains the strong tendency of smectite (or montmorillonite) particles to adsorb cations in order to balance the high negative charge. As can be seen, zeta potential values decrease in absolute value with increasing the amount of $\mathrm{TiO}_{2}$ in $\mathrm{B}-\mathrm{TiO}_{2}$ composites. This result was expected because the screening effects of sheets charges of bentonite with $\mathrm{TiO}_{2}$ particles will make the number of negative charges less important. Furthermore, the decrease of zeta potential in absolute value correlates to the creation of clusters of bridging flocculation at high $\mathrm{TiO}_{2}$ content, which leads to $\mathrm{B}-\mathrm{TiO}_{2}$ composites having less mobility in water.

\section{Effect of $\mathrm{TiO}_{2}$ content on the removal of crystal violet and hexavalent chromium}

Removal of crystal violet: The results of the decolorization of crystal violet using different $\mathrm{B}-\mathrm{TiO}_{2}$ samples with different $\mathrm{TiO}_{2}$ ratios under natural sunlight irradiation compared with dark adsorption are represented in Figure 8 and summarized in Table 2. The experiences of $\mathrm{CV}$ decolorization were carried out in $\mathrm{pH}$ range around 6.5 based on the results of our previous work [2]. As discussed in our previous paper [15], the morphology of this composite allows to combine both adsorption and photocatalytic reaction to remove dyes from water. In order to evaluate the contribution of adsorption and photocatalysis on the total removal for each photocatalyst, we supposed that the total removed quantity of crystal violet (under irradiation) is equal to the sum of: the adsorbed quantity in dark, the removed quantity by photolysis and the removed quantity by photocatalysis, while the latter may be calculated by subtraction.

Photolysis of $\mathrm{CV}$ solution at $10^{-4} \mathrm{M}$ under sunlight was around $7 \%$ after $4 \mathrm{~h}$ that corresponds to a CV photolysed quantity of $0.017 \times$ $10^{-4}$ moles. Adsorption results show that the adsorption rate of crystal violet and the adsorbed quantity (mol) decrease with the increase of $\mathrm{TiO}_{2}$ amount in the composite where sample of $5 \%$ of $\mathrm{TiO}_{2}$ has the highest adsorption values. This could be explained by the decrease of bentonite porosity by increasing $\mathrm{TiO}_{2}$ particles in the interlayers. According to SEM results, the surface of montmorillonite is less porous when the amount of $\mathrm{TiO}_{2}$ is high (at $30 \%$ ). Furthermore, XRD analysis demonstrates that the intensity of basal spacing decreases with increasing on $\mathrm{TiO}_{2}$ content. Hence, adsorptive sites for crystal violet hosting decrease at high $\mathrm{TiO}_{2}$ content. On the other hand, zeta potential changing to less negative with $\mathrm{TiO}_{2}$ increasing has an important role in the adsorption of crystal violet, which is a cationic dye, where the electrostatic attractions between photocatalyst surface and dye molecules decrease.

Results of crystal violet removal under sunlight by different photocatalysts demonstrate the participation of the photocatalytic 
Citation: Djellabi R, Ghorab MF, Bianchi CL, Cerrato G, Morandi S (2016) Removal of Crystal Violet and Hexavalent Chromium using TiO ${ }_{2}$-Bentonite under Sunlight: Effect of $\mathrm{TiO}_{2}$ Content. J Chem Eng Process Technol 7: 276. doi:10.4172/2157-7048.1000276

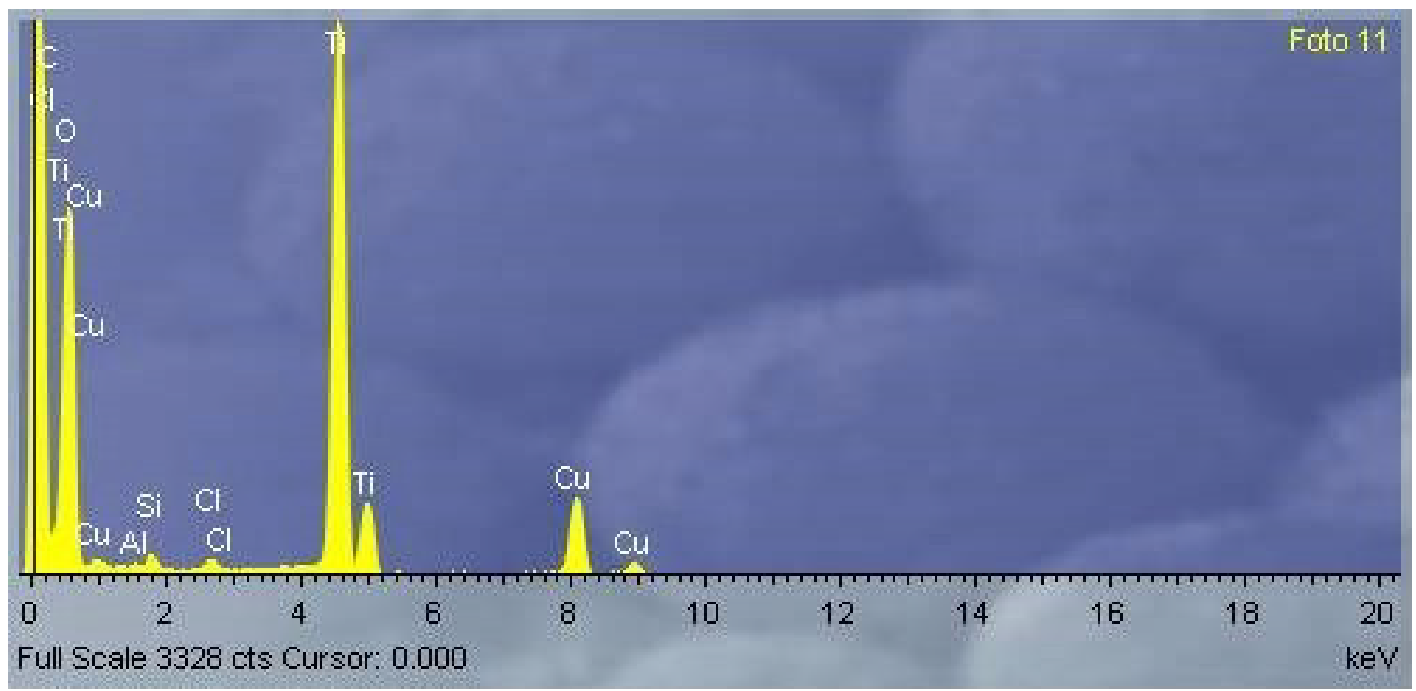

Figure 7: EDX spectrum of $\mathrm{B}-\mathrm{TiO}_{2}(20 \%)$ sample.

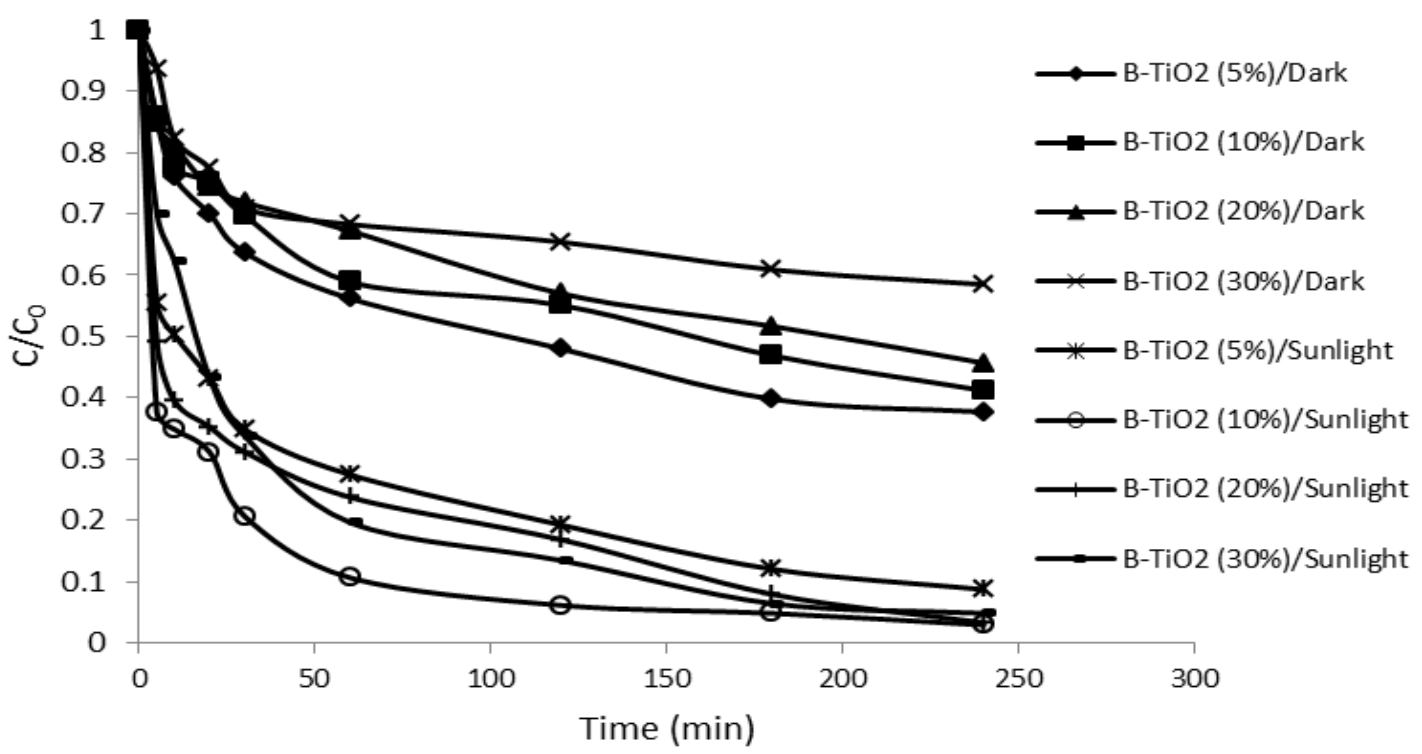

Figure 8: Removal of crystal violet using different $\mathrm{B}^{-\mathrm{TiO}_{2}}$ photocatalysts in dark and under sunlight irradiation. $\mathrm{Mass}$ of $\mathrm{B}-\mathrm{TiO}{ }_{2}: 0.16 \mathrm{~g} / \mathrm{L},[\mathrm{CV}]: 10^{-4} \mathrm{M}$, $\mathrm{pH}: 6.5$.

\begin{tabular}{|c|c|c|c|c|}
\hline & $\mathrm{B}-\mathrm{TiO}_{2}(5 \%)$ & $\mathrm{B}-\mathrm{TiO}_{2}(10 \%)$ & $\mathrm{B}-\mathrm{TiO}_{2}(20 \%)$ & $\mathrm{B}-\mathrm{TiO}_{2}(30 \%)$ \\
\hline Zeta Potential (mV) & -49.60 & -32.90 & -31.00 & -28.70 \\
\hline Mobility (umcm/V.s) & -3.890 & -2.564 & -2.419 & -2.221 \\
\hline
\end{tabular}

Table 1: Summary of zeta potential and mobility results of photocatalyst samples.

\begin{tabular}{|c|c|c|c|c|}
\hline & $\mathrm{B}-\mathrm{TiO}_{2}(5 \%)$ & $\mathrm{B}^{-\mathrm{TiO}_{2}}(\mathbf{1 0} \%)$ & $\mathrm{B}-\mathrm{TiO}_{2}(20 \%)$ & $\mathrm{B}-\mathrm{TiO}_{2}(30 \%)$ \\
\hline Removed rate under dark (\%) & 62.20 & 58.77 & 56.20 & 37.61 \\
\hline Adsorbed quantity $(\mathrm{mol}) \times 10^{-4}$ & 0.155 & 0.147 & 0.140 & 0.103 \\
\hline Removed rate under sunlight (\%) & 91.20 & 97.00 & 96.60 & 95.10 \\
\hline Total removed quantity $(\mathrm{mol}) \times 10^{-4}$ & 0.228 & 0.242 & 0.241 & 0.237 \\
\hline Removed quantity by photocatalysis $(\mathrm{mol}) \times 10^{-4}$ & 0.056 & 0.078 & 0.084 & 0.117 \\
\hline
\end{tabular}

Table 2: Effect of $\mathrm{TiO}_{2}$ content in $\mathrm{B}-\mathrm{TiO}_{2}$ on adsorption and photoactivity for CV removal (Initial quantity of crystal violet (mol): $0.25 \times 10^{-4}$; Photolysed quantity (mol): 0.017 $\left.\times 10^{-4}\right)$. 
Citation: Djellabi R, Ghorab MF, Bianchi CL, Cerrato G, Morandi S (2016) Removal of Crystal Violet and Hexavalent Chromium using TiO ${ }_{2}$-Bentonite under Sunlight: Effect of $\mathrm{TiO}_{2}$ Content. J Chem Eng Process Technol 7: 276. doi:10.4172/2157-7048.1000276

action to degrade crystal violet molecules. We used the term "removal" because it involves adsorption, photocatalysis and photolysis reactions. The rate of total removal show that samples of $\mathrm{B}^{-\mathrm{TiO}_{2}}(10 \%)$ and $\mathrm{B}_{-} \mathrm{TiO}_{2}(20 \%)$ exhibit the highest values. However, the removed amount of CV per mol by photocatalysis action increases with the increase of $\mathrm{TiO}_{2}$ content. It is worth to mention that, in the case of $\mathrm{B}_{-} \mathrm{TiO}_{2}(10 \%)$, the removal process under sunlight is very fast in the first few minutes (62.3\% at 5 minutes). This is due to a good suitability between photocatalyst properties including high porosity, negative surface charge and $\mathrm{TiO}_{2}$ particle distribution leading to a fast removal behavior as a synergistic effect of direct adsorption and photocatalytic degradation. The same manner for $\mathrm{B}-\mathrm{TiO}_{2}(20 \%)$ during the first minutes, nevertheless, the process is less faster with the time.

If we compare the behavior of $\mathrm{B}-\mathrm{TiO}_{2}(5 \%)$ and $\mathrm{B}-\mathrm{TiO}_{2}(30 \%)$, we can conclude that the processes of adsorption and photocatalysis are inversed. $\sim 91 \%$ as a total removed rate by $\mathrm{B}-\mathrm{TiO}_{2}(5 \%)$ corresponds to $\sim 62 \%$ by adsorption, $\sim 7 \%$ by direct photolysis and only $\sim 22 \%$ by photocatalysis action. The scarce performance of this sample is most likely due to the low $\mathrm{TiO}_{2}$ content. However, $\sim 95 \%$ as a total removed rate by $\mathrm{B}^{-\mathrm{TiO}_{2}}(30 \%)$ corresponds to $\sim 41 \%$ by adsorption, $\sim 7 \%$ by direct photolysis and $\sim 47 \%$ by photocatalysis action. In this case, photocatalysis reaction is predominant to remove $\mathrm{CV}$ molecules. Furthermore, for $\mathrm{B}-\mathrm{TiO}_{2}(30 \%)$ we note that the removal process at the beginning (after $\sim 30$ minutes) is too slow if compared to the other samples, because the attraction and the adsorption of molecules onto its surface take place with a very slow speed, reflecting its properties.

At the $\mathrm{B}-\mathrm{TiO}_{2}$ surface, two mechanisms can alternatively take place (i): CV molecules directly access to bentonite sheets following by simple adsorption or further degradation by hydroxyls produced by $\mathrm{TiO}_{2}$. During the degradation reaction, the adsorption plays a determinate role as a first step for accruing the photocatalytic action as the adsorbed molecules have an intrinsically higher priority to be reacted with hydroxyl radicals than molecules in the solution. This removal process is very fast because the attraction/adsorption between cationic dye molecules and negative bentonite is very quick. (ii): $\mathrm{CV}$ molecules directly adsorb/depose onto the $\mathrm{TiO}_{2}$ particles to induce the photocatalytic degradation. This mechanism is observed when the material surface is covered by $\mathrm{TiO}_{2}$. As the attraction between crystal violet molecules and $\mathrm{TiO}_{2}$ is less important than that with bentonite, in this case the removal process may be slower than the first mechanism.

However, both mentioned mechanisms can take place at the same time: therefore, for small $\mathrm{TiO}_{2}$ content $(10 \%)$, mechanism (i) is more pronounced, whereas for high $\mathrm{TiO}_{2}$ content (30\%), mechanism (ii) may be the predominant pathway.

Removal of hexavalent chromium: The reduction of $\mathrm{Cr}$ (VI) was studied in acidic medium (at pH: 2.2) based on the results of our previous work [9]. This is necessary in order to ensure a high difference between the energy level of the conduction band (ECB) of $\mathrm{TiO}_{2}$ and the redox potential for $\mathrm{Cr}(\mathrm{VI})$ species $\left(\mathrm{E}_{0} \mathrm{Cr}(\mathrm{VI}) / \mathrm{Cr}\right.$ (III)). Tartaric acid was used as whole scavenger with a concentration of $40 \mathrm{ppm}$. Its principal role is the separation of pairs (electron/hole) by scavenging the photogenerated holes, thus (i) decreasing the chance of charges (electron/hole) recombination and (ii) setting free more electrons in the conduction band available to reduce $\mathrm{Cr}$ (VI) ions. Furthermore, it reacts with produced ${ }^{\circ} \mathrm{OH}$ which possesses a high oxidizing potential and therefore limits the oxidation of the produced Cr (III) species to $\mathrm{Cr}$ (VI) species. Experimental results of dark adsorption and photoreduction in the presence of tartaric acid under sunlight are reported in Figure 9.

Direct photolysis of $\mathrm{Cr}(\mathrm{VI})$ species in the presence of tartaric acid was negligible (around 1.3\% after $4 \mathrm{~h}$ ). In addition, $\mathrm{Cr}(\mathrm{VI})$ adsorption rates were few and similar for all $\mathrm{B}-\mathrm{TiO}_{2}$ photocatalysts at $\sim 12 \%$, because the repulsive effects between negative charge of $\mathrm{Cr}$ (VI) species and the negative charge of bentonite. Even if the increasing of the $\mathrm{TiO}_{2}$ content brings about changes in both zeta potential and porosity of the materials, it does not affect the adsorption of $\mathrm{Cr}$ (VI) anionic species. However, it is worth to mention that the positive edges charges accounting from 5 to $10 \%$ of the total charges of bentonite can participate to bond $\mathrm{Cr}(\mathrm{VI})$ species. Besides, tartaric acid molecules may chelate $\mathrm{Cr}(\mathrm{VI})$ leads to fix into the bentonite surface.

On the other hand, under sunlight, the efficiency of Cr (VI)

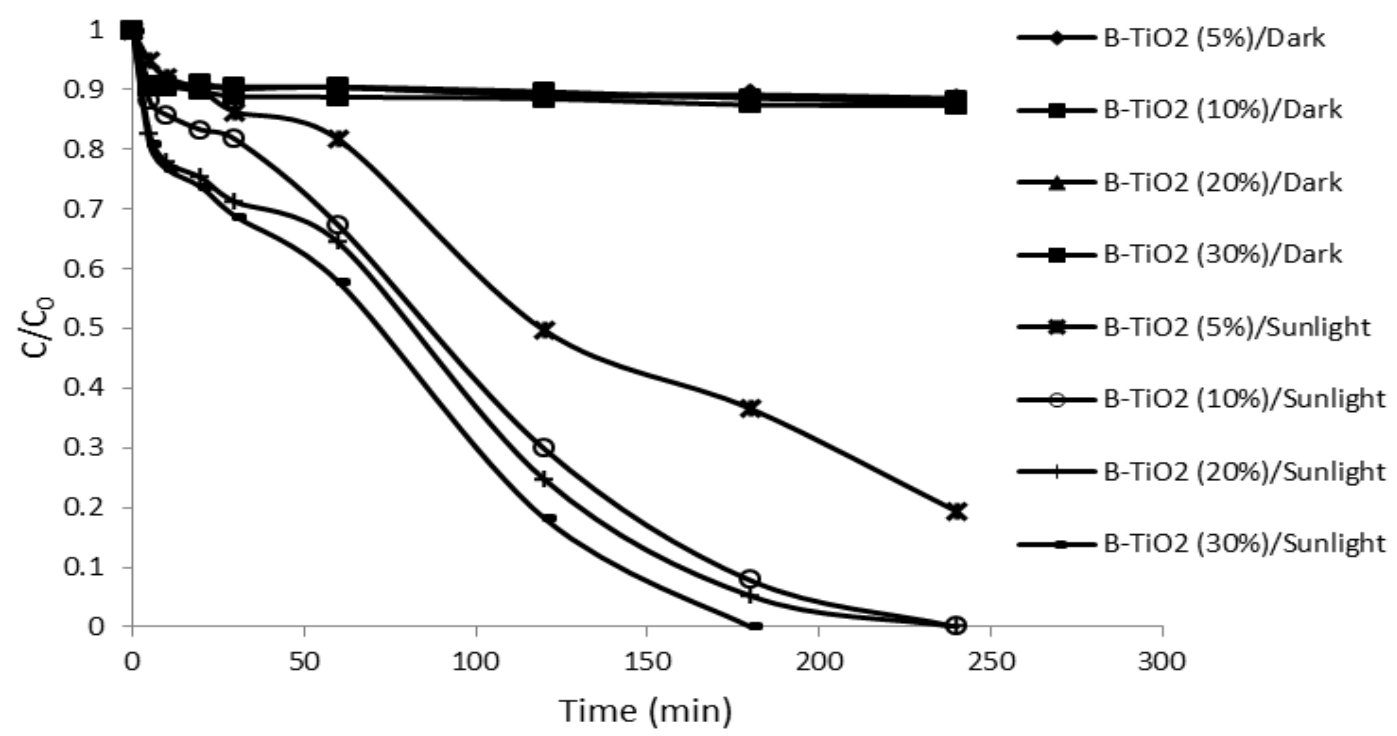

Figure 9: Removal of hexavalent using different $\mathrm{B}_{-} \mathrm{TiO}_{2}$ photocatalysts in dark and under sunlight irradiation. $\mathrm{Mass}$ of $\mathrm{B}-\mathrm{TiO}{ }_{2}: 0.2 \mathrm{~g} / \mathrm{L},[\mathrm{Cr}(\mathrm{VI})]$ : $30 \mathrm{ppm}, \mathrm{pH}: 2.2$, [acid tartaric]: $40 \mathrm{ppm}$. 
Citation: Djellabi R, Ghorab MF, Bianchi CL, Cerrato G, Morandi S (2016) Removal of Crystal Violet and Hexavalent Chromium using TiO ${ }_{2}$-Bentonite under Sunlight: Effect of $\mathrm{TiO}_{2}$ Content. J Chem Eng Process Technol 7: 276. doi:10.4172/2157-7048.1000276

Page 8 of 8

\begin{tabular}{|c|c|c|c|c|}
\hline & ${\mathrm{B}-\mathrm{TiO}_{2}}_{2}(5 \%)$ & $\mathrm{B}-\mathrm{TiO}_{2}(10 \%)$ & $\mathrm{B}-\mathrm{TiO}_{2}(20 \%)$ & ${\mathrm{B}-\mathrm{TiO}_{2}}_{2}(30 \%)$ \\
\hline Removed rate under dark (\%) & 11.40 & 12.60 & 12.40 & 11.90 \\
\hline Adsorbed quantity $(\mathrm{mol}) \times 10^{-4}$ & 0.164 & 0.181 & 0.178 & 0.171 \\
\hline Removed rate under sunlight (\%) & 89.60 & 100 & 100 & 100 \\
\hline Total removed quantity $(\mathrm{mol}) \times 10^{-4}$ & 1.162 & 1.442 & 1.246 & 1.442 \\
\hline Reduced quantity by photocatalysis $(\mathrm{mol}) \times 10^{-4}$ & 0.980 & 1.242 & 1.246 & 1.253 \\
\hline
\end{tabular}

Table 3: Effect of $\mathrm{TiO}_{2}$ content in $\mathrm{B}^{-} \mathrm{TiO}_{2}$ on adsorption and photoactivity for $\mathrm{Cr}(\mathrm{VI})$ removal (Initial quantity of $\mathrm{Cr}(\mathrm{VI})(\mathrm{mol}): 1.442 \times 10^{-4}$; $\mathrm{Photolysed} \mathrm{quantity} \mathrm{(mol):} 0.018$ $\left.\times 10^{-4}\right)$.

removal is more pronounced with the increase of $\mathrm{TiO}_{2}$ content. Sample of $\mathrm{B}^{-\mathrm{TiO}_{2}}(30 \%)$ ensures a total removal of $\mathrm{Cr}(\mathrm{VI})$ at $30 \mathrm{ppm}$ after $3 \mathrm{~h}$, while both $\mathrm{B}-\mathrm{TiO}_{2}(10 \%)$ and $\mathrm{B}-\mathrm{TiO}_{2}(20 \%)$ samples achieved a total removal after $4 \mathrm{~h}$. Surprisingly, the $\mathrm{B}-\mathrm{TiO}_{2}(5 \%)$ sample ensures a removal rate of $\sim 80 \%$. This result was not expected because of the very small $\mathrm{TiO}_{2}$ content. However, this low $\mathrm{TiO}_{2}$ content might lead to form $\mathrm{TiO}_{2}$ particles of very small size possessing such a good distribution on the bentonite surface, thus leading to a relatively high photocatalytic activity.

From Table 3, it can be seen that the photocatalysis action is the main reaction for reducing $\mathrm{Cr}(\mathrm{VI})$ species, while the participation of adsorption and photolysis is almost negligible.

As Cr (VI) adsorb very slight onto the bentonite surface, the removal of $\mathrm{Cr}(\mathrm{VI})$ species from the solution occurred mainly by a reduction reaction through two principal steps: (i) negatively charged species $\left(\mathrm{Cr}_{2} \mathrm{O}_{7}{ }^{2-}, \mathrm{HCrO}_{4}^{-}\right)$are reduced to positive species $(\mathrm{Cr}(\mathrm{III}))$ by electrons coming from the conduction band of $\mathrm{TiO}_{2}$ particles deposited on the bentonite material; (ii) the second important step caused by the montmorillonite support is the transfer of $\mathrm{Cr}$ (III) cations from the $\mathrm{TiO}_{2}$ particles to the negative inter-layer pores where binding strength can take place between $\mathrm{Cr}$ (III) and the negative charge of montmorillonite sheets. This positive effect avoids the penetration of $\mathrm{Cr}$ (III) species in the solution and ensures a continuous contact of $\mathrm{Cr}$ (VI) species with photocatalytic $\mathrm{TiO}_{2}$ sites.

\section{Conclusions}

The present work shows the effect of $\mathrm{TiO}_{2}$ content in photoactive bentonite- $\mathrm{TiO}_{2}$ on the removal of crystal violet and hexavalent chromium from water under natural solar light. In general, $\mathrm{TiO}_{2}$ content affects both the physico-chemical properties and the photocatalytic activity of synthesized photocatalysts. On one hand, on increasing the $\mathrm{TiO}_{2}$ content the $\mathrm{CV}$ adsorption rate decreases: this is due to the decrease of both porosity and negative charges present at the surface. On the other hand, Cr (VI) species adsorb slightly onto all $\mathrm{B}-\mathrm{TiO}_{2}$ samples, because the high negative charge of bentonite leads to a repulsive effect with $\mathrm{Cr}$ (VI) species. However, under sunlight, the amount of CV molecules degraded by photocatalysis action increases as a function of the $\mathrm{TiO}_{2}$ content. Being the total removal of $\mathrm{CV}$ the sum of adsorption, photocatalysis and photolysis, $\mathrm{B}-\mathrm{TiO}_{2}(10 \%)$ exhibits the highest rate of removal because of a good compromise between adsorption capacity and photo-catalytic activity. Furthermore, the removal of $\mathrm{Cr}(\mathrm{VI})$ occurred mainly by a photoreduction reaction via electrons generated from $\mathrm{TiO}_{2}$ under sunlight. The process of $\mathrm{Cr}$ (VI) reduction is more efficient and faster with $\mathrm{TiO}_{2}$ increasing amounts.

\section{Acknowledgements}

The authors acknowledge the financial support of the Ministry of Higher Education (Algeria). The authors would like to thank Prof G. Cerrato and and Dr. S. Morandi, Università degli Studi di Milano (Torino), extending their characterization facilities and for useful discussions.

\section{References}

1. Chong MN, Sharma AK, Burn SS, Saint CP (2012) Feasibility study on the application of advanced technologies for decentralized wastewater treatment. J Clean Prod 35: 230-238.

2. Djellabi R, Ghorab MF (2013) Solar photocatalytic decolourization of crystal violet using supported $\mathrm{TiO}_{2}$ : effect of some parameters and comparative efficiency. Desalin Water Treat, pp: 1-7.

3. Ketir W, Bouguelia A, Trari M (2008) Photocatalytic removal of $\mathrm{M}(2+)(\mathrm{Ni}(2+)$ $\mathrm{Cu}(2+), \mathrm{Zn}(2+), \mathrm{Cd}(2+), \mathrm{Hg}(2+)$ and $\mathrm{Ag}(+))$ over new catalyst $\mathrm{CuCrO}(2) . \mathrm{J}$ Hazard Mater 158: 257-263.

4. Djellabi R, Ghorab MF (2014) Photoreduction of toxic chromium using $\mathrm{TiO}_{2}$ immobilized under natural sunlight: effects of some hole scavengers and process parameters. Desalin Water Treat, pp: 1-8.

5. Rajeshwar K, Osugi ME, Chanmanee W, Chenthamarakshan CR, Zanon MVB, et al. (2008) Heterogeneous photocatalytic treatment of organic dyes in air and aqueous media. J Photochem Photobiol C: Photochem Rev 9: 171-194.

6. Fujishima A, Zhang X, Tryk DA (2007) Heterogeneous photocatalysis: from water photolysis to applications in environmental cleanup. Int $\mathrm{J}$ Hydrogen Energy 32: 2664-2672.

7. Vohra MS, Tanaka K (2003) Photocatalytic degradation of aqueous pollutants using silica-modified TiO(2). Water Res 37: 3992-3996.

8. Chen H, Lee SW, Kim TH, Hur BY (2006) Photocatalytic decomposition of benzene with plasma sprayed $\mathrm{TiO}_{2}$-based coatings on foamed aluminum. J Eur Ceram Soc 26: 2231-2239

9. Zhang W, Zou L, Wang L (2009) Photocatalytic $\mathrm{TiO}_{2} /$ adsorbent nanocomposites prepared via wet chemical impregnation for wastewater treatment: A review. Appl Catal A 371: 1-9.

10. Dvininov E, Popovici E, Pode R, Cocheci L, Barvinschi P, et al. (2009) Synthesis and characterization of $\mathrm{TiO}_{2}$-pillared Romanian clay and their application for azoic dyes photodegradation. J Hazard Mater 167: 1050-1056.

11. Aranda P, Kun R, Martín-Luengo MA, Letaïef S, Dékány I, et al. (2008) Titaniasepiolite nanocomposites prepared by a surfactant templating colloidal route. Chem Mater 20: 84-91.

12. Bouna L, Rhouta B, Amjoud M, Maury F, Lafont MC, et al. (2011) Characterization and photocatalytic activity of $\mathrm{TiO}_{2}$ supported natural palygorskite microfibers. Appl Clay Sci 52: 301-311.

13. Kameshima Y, Tamura Y, Nakajima A, Okada K (2009) Reparation and properties of TiO2/montmorillonite composites. App Clay Sci 45: 20-23.

14. Chen D, Zhu Q, Zhou F, Deng X, Li F (2012) Synthesis and photocatalytic performances of the TiO2 pillared montmorillonite. J Hazard Mater 235-236: 186-93.

15. Djellabi R, Ghorab MF, Cerrato G, Morandi S, Gatto S, et al. (2014) Photoactive $\mathrm{TiO}_{2}$-montmorillonite composite for degradation of organic dyes in water. $J$ Photochem Photobiol A 295: 57-63.

16. Li Y, Liu JR, Jia SY, Guo JW, Zhuo J, et al. (2012) TiO pillared montmorillonite as a photoactive adsorbent of arsenic under UV irradiation. Chem Eng J 191: 66-74.

17. Kota J, Stasicka Z (2000) Chromium occurrence in the environment and methods of its speciation. Environ Pollut 107: 263-283.

18. Duc M, Gaboriaud F, Thomas F (2005) Sensitivity of the acid-base properties of clays to the methods of preparation and measurement. J Colloid Interface Sci 289: 139-147. 